\title{
Light Quality Affects Water Use of Sweet Basil by Changing Its Stomatal Development
}

\author{
Sungeun Lim 1 and Jongyun Kim * (1)
}

check for

updates

Citation: Lim, S.; Kim, J. Light Quality Affects Water Use of Sweet Basil by Changing Its Stomatal Development. Agronomy 2021, 11, 303. https://doi.org/10.3390/ agronomy11020303

Academic Editor: Ajit Govind Received: 15 January 2021

Accepted: 5 February 2021

Published: 9 February 202

Publisher's Note: MDPI stays neutral with regard to jurisdictional claims in published maps and institutional affiliations.

Copyright: (C) 2021 by the authors Licensee MDPI, Basel, Switzerland. This article is an open access article distributed under the terms and conditions of the Creative Commons Attribution (CC BY) license (https:// creativecommons.org/licenses/by/ $4.0 /)$
Department of Plant Biotechnology, Korea University, Seoul 02841, Korea; eye0425@korea.ac.kr

* Correspondence: jongkim@korea.ac.kr
Abstract: Different light qualities affect plant growth and physiological responses, including stomatal openings. However, most researchers have focused on stomatal responses to red and blue light only, and the direct measurement of evapotranspiration has not been examined. Therefore, we quantified the evapotranspiration of sweet basil under various red (R), green (G), and blue (B) combinations using light-emitting diodes (LEDs) and investigated its stomatal responses. Seedlings were subjected to five different spectral treatments for two weeks at a photosynthetic photon flux density of $200 \mu \mathrm{mol} \mathrm{m}{ }^{-2} \mathrm{~s}^{-1}$. The ratios of the RGB light intensities were as follows: $\mathrm{R} 100 \%\left(\mathrm{R}_{100}\right)$, $R: G=75: 25\left(R_{75} G_{25}\right), R: B=75: 25\left(R_{75} B_{25}\right), R: G: B=60: 20: 20\left(R_{60} G_{20} B_{20}\right)$, and R:G:B = 31:42:27 $\left(\mathrm{R}_{31} \mathrm{G}_{42} \mathrm{~B}_{27}\right)$. During the experiment, the evapotranspiration of the plants was measured using load cells. Although there were no significant differences in growth parameters among the treatments, the photosynthetic rate and stomatal conductance were higher in plants grown under blue LEDs $\left(\mathrm{R}_{75} \mathrm{~B}_{25}\right.$, $\mathrm{R}_{60} \mathrm{G}_{20} \mathrm{~B}_{20}$, and $\mathrm{R}_{31} \mathrm{G}_{42} \mathrm{~B}_{27}$ ) than in the $\mathrm{R}_{100}$ treatment. The amount of water used was different among the treatments $\left(663.5,726.5,728.7,778.0\right.$, and $782.1 \mathrm{~mL}$ for the $\mathrm{R}_{100}, \mathrm{R}_{75} \mathrm{G}_{25}, \mathrm{R}_{60} \mathrm{G}_{20} \mathrm{~B}_{20}, \mathrm{R}_{75} \mathrm{~B}_{25}$, and $R_{31} G_{42} B_{27}$ treatments, respectively). The stomatal density was correlated with the blue light intensity $(p=0.0024)$ and with the combined intensity of green and blue light $(p=0.0029)$; therefore, green light was considered to promote the stomatal development of plants together with blue light. Overall, different light qualities affected the water use of plants by regulating stomatal conductance, including changes in stomatal density.

Keywords: evapotranspiration; stomatal density; green light; Ocimum basilicum; load cell; controlled environment

\section{Introduction}

Indoor farming has emerged as a new form of agriculture for the future [1]; therefore, considerable effort has been made to understand plant physiology to enhance the productivity of plant production by correctly controlling their growth environment. Artificial light sources have been developed to replace sunlight to grow plants in controlled environmental production systems, and many studies have been conducted to promote the efficiency of the artificial light source and effectively use it for plant production $[2,3]$. Concurrently, researchers have also aimed to enhance resource use efficiency, including water use efficiency, in indoor farming for sustainable development $[4,5]$.

Plants are greatly affected by light environmental factors, including intensity, direction, wavelength, and light duration. Among these, the study of light quality has been accelerated by the development of light-emitting diode (LED) technology, which is one of the most predominant artificial light sources for plant production [6]. LEDs have many advantages, including small size, durability, low energy consumption, low heat emission, and longevity compared to conventional light sources. LEDs can also provide a specific light spectrum; thus, they are appropriate for studying the effect of light quality on plant behaviors for observing the response of plants to a target wavelength without the interference of other wavelength ranges, and various combinations of light wavelengths can be applied [7]. 
Previous studies using LEDs revealed that light quality affects the diverse responses of plants including physiological activities, growth, and morphology in various species [8-10]. Most previous studies used red light, which was considered the primary wavelength required for plant growth; however, the role of blue light started being highlighted, as the engagement of blue light in various plant physiological processes was revealed by researchers [11]. The addition of blue light to the background of red light enhanced the photosynthetic rate and increased the biomass production of plants compared to irradiating plants with red light alone [12,13]. The effect of green light has also been studied together with red and blue light. According to the studies conducted to date, green light induces shade avoidance in plants and promotes the vegetative growth of plants by deeply penetrating the plant canopy and increasing the photosynthesis of leaves in the lower canopy $[14,15]$.

Light quality also affects the stomatal responses of plants. Sharkey and Raschke [16] reported that red and blue light together act on stomatal opening; however, blue light opens stomata more effectively than red light. Blue light increased the stomatal conductance of plants by increasing both the stomatal aperture and stomatal density of plants compared to red light [17-19]. Green light exerted only a slight influence on stomatal opening when provided as monochromatic light; however, the adverse effect of green light on the stomatal opening induced by blue light was reported by Frechilla et al. [20]. Changes in the stomatal response could consequently affect the water use of plants as well as their photosynthesis. Pennisi et al. [21] conducted an experiment to compare the resource use efficiency of plants grown under various red:blue ratios and assessed their water use and stomatal conductance. The amount of water used by plants was determined by the remaining volume of nutrient solution in individual hydroponic systems at harvest. The water usage increased slightly as the proportion of red light to blue light increased, contrary to the result of stomatal conductance, which was due to the increased plant sizes with the increasing red light intensity. However, the effect of the stomatal response on the water use of plants was not evaluated, and the amount of water used by plants was not precisely quantified.

Although the stomatal response to light quality has been studied by many researchers, previous studies have only measured a part of the range of parameters that show the stomatal response, and the direct measurement of evapotranspiration under different light quality conditions has not yet been examined. Furthermore, there is limited information regarding the effect of green light on plant responses because most previous studies have focused on red and blue light. Therefore, the objective of the present study was to monitor and quantify the water use of sweet basil grown under various red (R), green $(G)$, and blue (B) (RGB) combinations by measuring the evapotranspiration of plants using load cells and investigating the overall growth, photosynthetic parameters, and stomatal development to identify the factors that contribute to the different water usage of plants.

\section{Materials and Methods}

\subsection{Plant Material and Growing Conditions}

The experiment was conducted at Korea University, Seoul, Korea, from 9 June to 30 July 2020. In a glass greenhouse, sweet basil seeds (Ocimum basilicum L., Asia Seed Co., Seoul, Korea) were sown in 128-cell plug trays with a germinating substrate containing sphagnum peat moss, perlite, dolomite lime, and wetting agent (Sunshine Mix \#5; Sun Gro Horticulture, Agawam, MA, USA). After 3 weeks, the seedlings were transplanted into $10-\mathrm{cm}$ round plastic pots using a soilless substrate with a similar composition to a germinating substrate (Sunshine Mix \#4; Sun Gro Horticulture) and controlled-release fertilizer (Multicote 6; NPK 14-14-14, Haifa Chemicals, Israel) was incorporated into the pots at a rate of $4 \mathrm{~g} \mathrm{~L}^{-1}$. Two weeks after transplanting, all the plants were transferred to an environmentally controlled plant growth chamber for an acclimation period of a week. One day before the treatment, 45 plants at similar growth stages were selected and used for the experiment. During the experiment, the plants were fully irrigated to saturation every alternate day. The average hourly temperature, relative humidity, and $\mathrm{CO}_{2}$ concentration 
were $25.0 \pm 0.4{ }^{\circ} \mathrm{C}, 62.8 \pm 9.7 \%$, and $582 \pm 142 \mu \mathrm{mol} \mathrm{mol}^{-1}$ (mean \pm SD), respectively, during the experiment.

\subsection{Light Treatments}

The plants were irradiated with five different spectra during the experiment, and the ratios of the $R, G$, and $B$ light intensities were as follows: $R$ light $100 \%\left(R_{100}\right), R: G=75: 25$ $\left(\mathrm{R}_{75} \mathrm{G}_{25}\right), \mathrm{R}: \mathrm{B}=75: 25\left(\mathrm{R}_{75} \mathrm{~B}_{25}\right), \mathrm{R}: \mathrm{G}: \mathrm{B}=60: 20: 20\left(\mathrm{R}_{60} \mathrm{G}_{20} \mathrm{~B}_{20}\right)$, and R:G:B=31:42:27 $\left(\mathrm{R}_{31} \mathrm{G}_{42} \mathrm{~B}_{27}\right)$ (Figure 1). The $R_{31} G_{42} B_{27}$ treatment mimicked the sunlight spectrum measured in the experimental greenhouse at noon. To provide the specific light quality treatments, a customized LED dimming system equipped with six LED bars each consisting of red $(600-700 \mathrm{~nm}$, peak $=664 \mathrm{~nm})$, green $(485-600 \mathrm{~nm}$, peak $=524 \mathrm{~nm})$, and blue $(400-485 \mathrm{~nm}$, peak $=451 \mathrm{~nm})$ LED chips (ESLEDs, Seoul, Korea) was used. Each R, G, and B diode was controlled to provide the target RGB ratios, and the ratios were confirmed using a spectroradiometer (SS-110; Apogee Instruments, Logan, UT, USA). During the acclimation period, the plants were grown under the $\mathrm{R}_{31} \mathrm{G}_{42} \mathrm{~B}_{27}$ LEDs. All the treatments delivered a photosynthetic photon flux density (PPFD) of $200 \mu \mathrm{mol} \mathrm{m}{ }^{-2} \mathrm{~s}^{-1}$ at the plant canopy for $16 \mathrm{~h} \mathrm{~d}^{-1}$. To maintain the same light intensity at the plant canopy as the plants grew, we readjusted the LED lights every 3 days using a spectroradiometer and quantum sensor (MQ-500; Apogee Instruments).
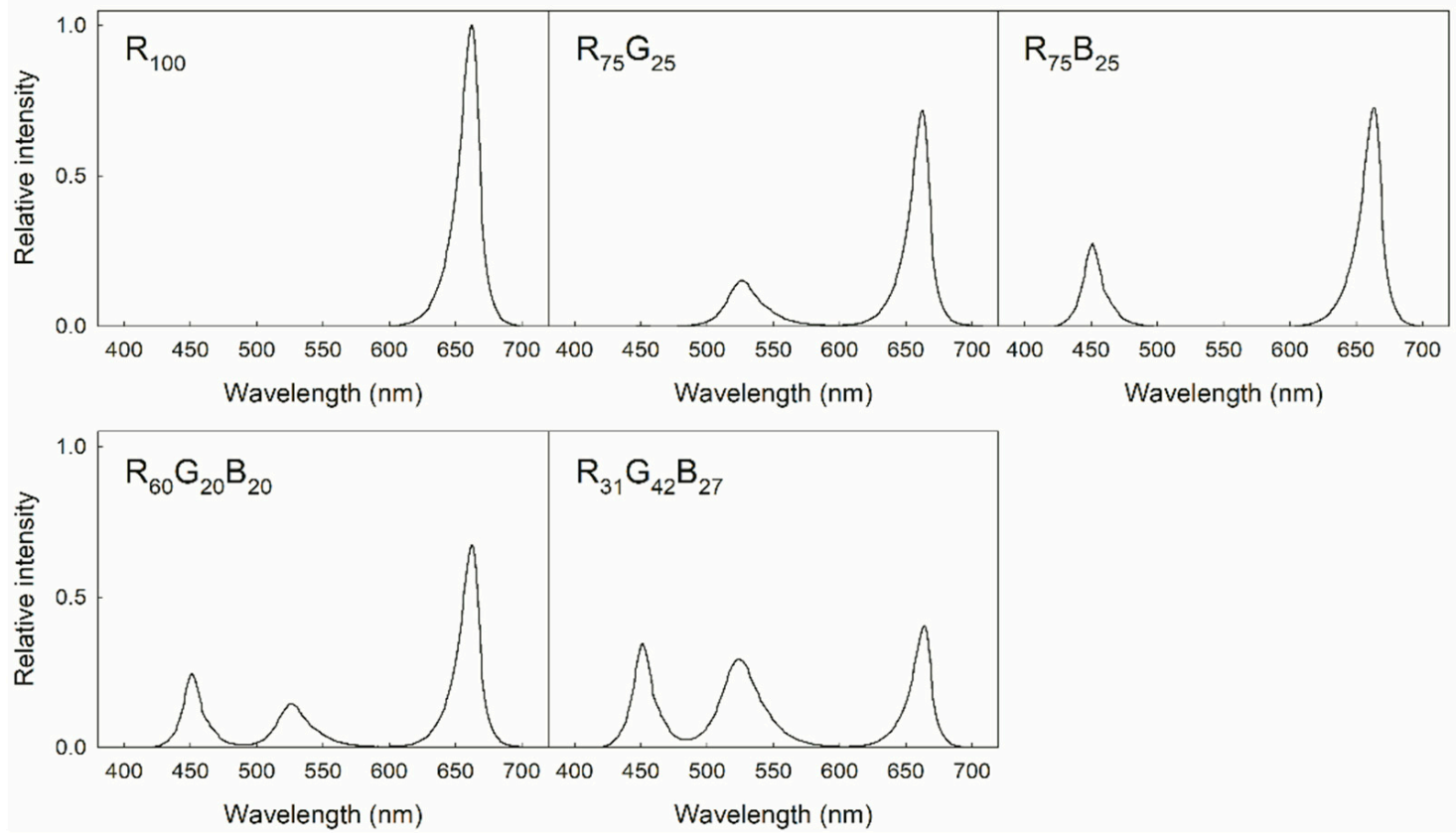

Figure 1. Spectral distributions of the five light quality treatments delivered by red [R $(600-700 \mathrm{~nm})$, peak $=664 \mathrm{~nm}]$, green [G $(485-600 \mathrm{~nm})$, peak $=524 \mathrm{~nm}]$, and blue $[\mathrm{B}(400-485 \mathrm{~nm})$, peak $=451 \mathrm{~nm}$ ] light-emitting diodes. The numbers after each waveband indicate the ratios of the intensities. The $R_{31} G_{42} B_{27}$ treatment mimics the sunlight spectrum measured in the experimental greenhouse.

\subsection{Evapotranspiration Measurements}

To measure the evapotranspiration of the plants, 15 individually calibrated load cells (BCL-1L; CAS Scale Korea, Seoul, Korea) (Figure 2) were connected to a data logger (CR1000; Campbell Scientific, Logan, UT, USA) via a multiplexer (AM 16/32B; Campbell Scientific). One pot per experimental unit was mounted on the load cell, and the weight of the pot was measured every $10 \mathrm{~s}$. Their average value was recorded every $30 \mathrm{~min}$. The change in pot weight ( $\Delta$ weight) was calculated by subtracting the current 30 -min average weight from the previous 30-min average weight, and the daily evapotranspiration of plants was determined based on the $\Delta$ weight data of that day. The weight change during 
the irrigation event was corrected. The plants on the load cells were harvested on the last day of the experiment.

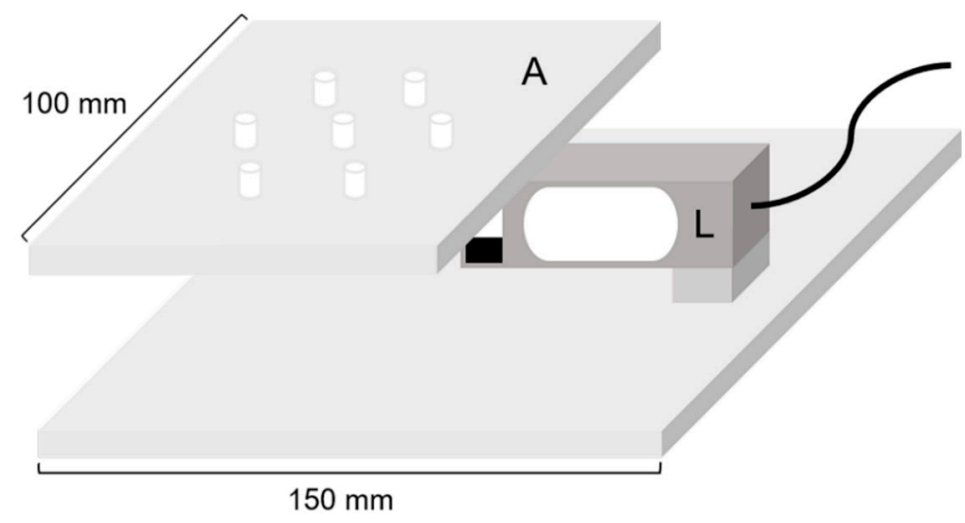

Figure 2. Diagram of the load cell. Pots were mounted on the acrylic plates attached to the load cells, and the leaching water was drained through the holes in the plate. A, acrylic plate; L, load cell.

\subsection{Photosynthetic Parameters and Growth Measurements}

To measure the physiological changes in the plants over 2 weeks, photosynthetic and growth parameters were measured on weekly basis. One plant from each experimental unit was used for weekly harvest at 0,7 , and 14 days after treatment (DAT). The canopy leaf temperature was measured at the position where the plants were grown using an infrared thermometer. The photosynthetic rate and stomatal conductance were measured on the uppermost, fully expanded leaves using a portable photosynthesis system (CIRAS-3; PP Systems, Amesbury, MA, USA) with similar conditions to the growth chamber. On the same leaves, the maximum quantum yield of PSII (Fv/Fm) was measured using a chlorophyll fluorometer (Junior PAM; Heinz Walz GmbH, Effeltrich, Germany) after dark acclimation for $20 \mathrm{~min}$. To assess plant growth, the chlorophyll content (SPAD), shoot fresh/dry weight, root fresh/dry weight, and leaf area were measured. The SPAD value was determined using a SPAD meter (SPAD-502; Minolta Corporation Ltd., Osaka, Japan). The dry weights of the shoots and roots were measured after drying the samples at $80{ }^{\circ} \mathrm{C}$ for a week in a drying oven. The leaf area was measured using a leaf area meter (LI-3100; LI-COR, Lincoln, NE, USA).

\subsection{Stomatal Analysis}

To assess the stomatal density and size, imprints from the abaxial surface of the uppermost, fully expanded leaves were taken. Transparent nail polish was applied to the abaxial surface of the tips of the attached leaves and transferred to microscope slides using clear tape [22]. One imprint per leaf was made. Images of the stomata were captured using a light microscope (CX31; Olympus Inc., Tokyo, Japan) equipped with a digital camera (YJO-301; Daemyung Optical, Seoul, Korea) and analyzed using ImageJ software (version 1.53a; National Institutes of Health, Bethesda, MD, USA). To determine the stomatal density, five photographs spanning an area of $0.2 \mathrm{~mm}^{2}$ were taken at different locations from each imprint. All stomata in the images were counted, and the average stomatal density of five images was expressed as the number of stomata over $1 \mathrm{~mm}^{2}$. Stomata size was measured by randomly taking 30 images of stomata from each imprint, and their guard cell length, guard cell width, and pore length were measured.

\subsection{Experimental Design and Statistical Analysis}

The experiment was designed as a randomized complete block design with five treatments and three blocks, and there were three plants in each experimental unit. The parameters among the treatments were analyzed by analysis of variance (ANOVA) followed by Duncan's multiple range test when there was a significant difference at $p<0.05$, using 
statistical analysis software (SAS 9.4; SAS Institute, Cary, NC, USA). The effect of the LED light on stomatal conductance and density and the relationship between stomatal density and conductance were analyzed via regression analysis using SigmaPlot (SigmaPlot 11.0; Systat Software Inc., San Jose, CA, USA).

\section{Results and Discussion}

\subsection{Overall Growth and Physiological Responses}

Sweet basil grown under different light spectra for 2 weeks showed no significant differences in canopy leaf temperature, chlorophyll content, and general growth parameters, including shoot fresh/dry weight, root fresh/dry weight, and leaf area (Table 1). Although previous studies indicated a significant influence of light quality on plant growth [21,23] our results showed that 2 weeks of light quality treatments did not significantly alter the additional growth of sweet basil grown under the same PPFD. This inconsistent result in the present study was likely due to the growth stages of the plants when the treatment was initiated and the treatment period. Most previous light quality experiments were conducted using young plants; therefore, the plants were exposed to specific light treatment from the early stages of growth until they were almost fully grown, thereby affecting the overall growth of the plants. However, the present study was conducted using 6-week-old sweet basil plants that had already reached a certain size and continued for only 2 weeks to minimize the variation in growth among the plants and compare the water use of plants under similar growth conditions.

Table 1. Canopy leaf temperature, chlorophyll content, and growth parameters of Ocimum basilicum measured at 0 , 7, and 14 days after the treatment (DAT). Plants were grown under five different combinations of red, green, and blue LEDs with the same light intensity for 14 days. The numbers after each waveband indicate the ratios of the intensities. The $R_{31} G_{42} B_{27}$ treatment mimics the sunlight spectrum measured in the experimental greenhouse.

\begin{tabular}{|c|c|c|c|c|c|c|c|}
\hline \multirow{2}{*}{$\begin{array}{c}\text { Growth } \\
\text { Parameters }\end{array}$} & \multirow{2}{*}{ DAT } & \multicolumn{5}{|c|}{ Treatment } & \multirow{2}{*}{ Significance } \\
\hline & & $\mathbf{R}_{100}$ & $\mathrm{R}_{75} \mathrm{G}_{25}$ & $\mathbf{R}_{75} \mathbf{B}_{25}$ & $\mathrm{R}_{60} \mathrm{G}_{20} \mathrm{~B}_{20}$ & $\mathbf{R}_{31} \mathbf{G}_{42} \mathbf{B}_{27}$ & \\
\hline \multirow{3}{*}{ Canopy leaf temperature $\left({ }^{\circ} \mathrm{C}\right)$} & 0 & 23.7 & 23.8 & 24.0 & 23.9 & 23.7 & NS \\
\hline & 7 & 23.6 & 24.1 & 23.6 & 23.4 & 23.8 & NS \\
\hline & 14 & 24.8 & 24.5 & 24.2 & 24.5 & 24.5 & NS \\
\hline \multirow{3}{*}{ Chlorophyll content (SPAD) } & 0 & 33.3 & 34.6 & 34.3 & 33.3 & 32.8 & NS \\
\hline & 7 & 37.2 & 38.2 & 37.8 & 37.6 & 37.9 & NS \\
\hline & 14 & 38.0 & 36.1 & 36.3 & 37.0 & 35.5 & NS \\
\hline \multirow{3}{*}{ Shoot fresh weight $(\mathrm{g})$} & 0 & 6.2 & 6.9 & 6.9 & 6.8 & 7.0 & NS \\
\hline & 7 & 14.0 & 14.5 & 14.2 & 14.2 & 14.3 & NS \\
\hline & 14 & 20.0 & 20.8 & 19.6 & 18.3 & 18.0 & NS \\
\hline \multirow{3}{*}{ Shoot dry weight (g) } & 0 & 0.47 & 0.53 & 0.52 & 0.51 & 0.52 & NS \\
\hline & 7 & 1.19 & 1.25 & 1.23 & 1.17 & 1.21 & NS \\
\hline & 14 & 1.86 & 1.96 & 1.93 & 1.83 & 1.90 & NS \\
\hline \multirow{3}{*}{ Root fresh weight (g) } & 0 & 1.05 & 0.93 & 1.05 & 1.12 & 1.28 & NS \\
\hline & 7 & 3.17 & 2.77 & 2.98 & 3.38 & 2.90 & NS \\
\hline & 14 & 5.91 & 4.57 & 4.92 & 4.61 & 5.28 & NS \\
\hline \multirow{3}{*}{ Root dry weight (g) } & 0 & 0.07 & 0.06 & 0.07 & 0.08 & 0.08 & NS \\
\hline & 7 & 0.22 & 0.19 & 0.22 & 0.23 & 0.19 & NS \\
\hline & 14 & 0.45 & 0.35 & 0.42 & 0.39 & 0.47 & NS \\
\hline \multirow{3}{*}{ Leaf area $\left(\mathrm{cm}^{2}\right)$} & 0 & 228 & 241 & 249 & 246 & 251 & NS \\
\hline & 7 & 462 & 493 & 479 & 481 & 474 & NS \\
\hline & 14 & 649 & 695 & 638 & 589 & 602 & NS \\
\hline
\end{tabular}

NS indicates non-significance at $p<0.05(n=3)$. 
In contrast, the light quality treatments induced significant differences in the photosynthetic rate and stomatal conductance among the treatments from 7DAT (Figure 3A,B). The photosynthetic rate and stomatal conductance were higher in plants grown under LEDs with blue light $\left(\mathrm{R}_{75} \mathrm{~B}_{25}, \mathrm{R}_{60} \mathrm{G}_{20} \mathrm{~B}_{20}\right.$, and $\left.\mathrm{R}_{31} \mathrm{G}_{42} \mathrm{~B}_{27}\right)$ than under the $\mathrm{R}_{100}$ treatment, regardless of the presence of green light. These results showed that the photosynthetic rate and stomatal conductance of plants increased when the plants were irradiated with blue light, with similar results reported in previous studies $[19,24,25]$. The positive correlation of stomatal conductance with blue light intensity is also displayed in Figure $4(p=0.0015)$, clearly suggesting that stomatal conductance increased with increasing blue light intensity. The Fv / Fm value of the $\mathrm{R}_{75} \mathrm{G}_{25}$ treatment sharply decreased at 14DAT, resulting in the lowest $\mathrm{Fv} / \mathrm{Fm}$ value among the treatments (Figure $3 \mathrm{C}$ ). The $\mathrm{R}_{75} \mathrm{~B}_{25}$ treatment showed the highest $\mathrm{Fv} / \mathrm{Fm}$ value among the treatments, and the other treatments displayed similar $\mathrm{Fv} / \mathrm{Fm}$ values.
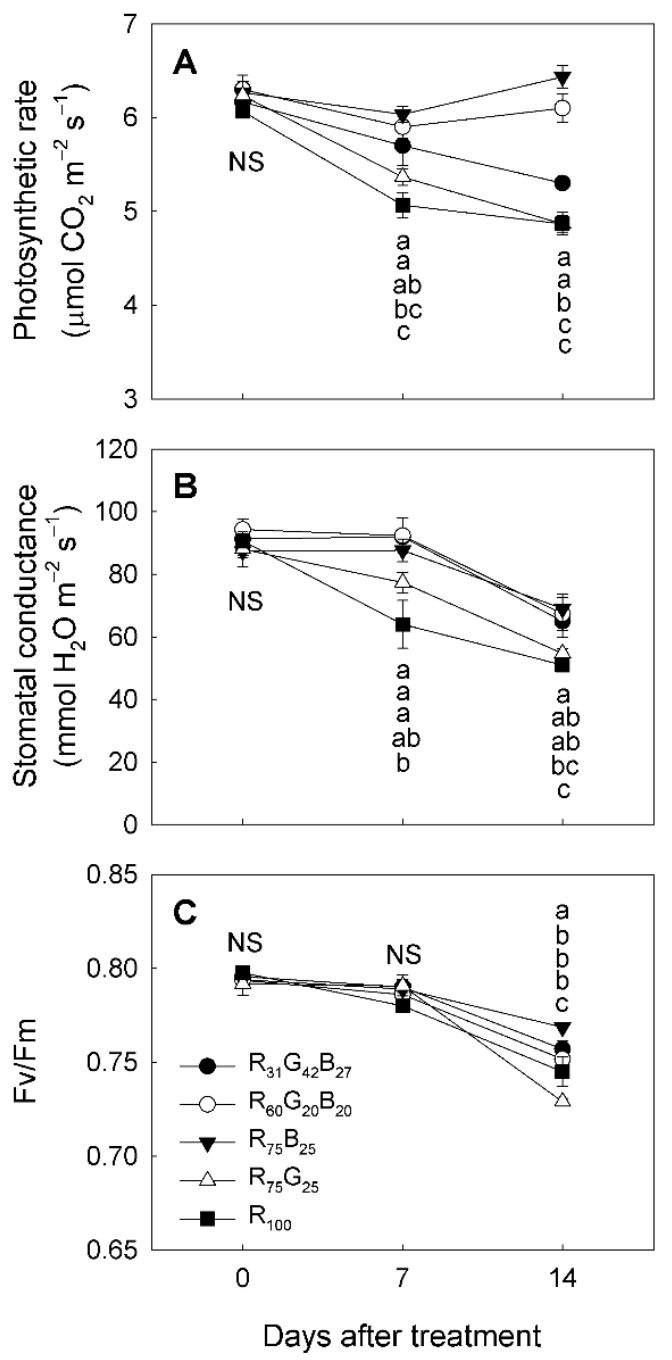

Figure 3. (A) Photosynthetic rate, (B) stomatal conductance, and (C) Fv/Fm of Ocimum basilicum grown under five different combinations of red, green, and blue LEDs with the same light intensity for 14 days. The numbers after each waveband indicate the ratios of the intensities. The $R_{31} G_{42} B_{27}$ treatment mimics the sunlight spectrum measured in the experimental greenhouse. Mean separation followed analysis of variance (ANOVA) with Duncan's multiple range test at $\alpha=0.05$. Means with the same letter are not significantly different. Error bars indicate the standard error $(n=3)$. 


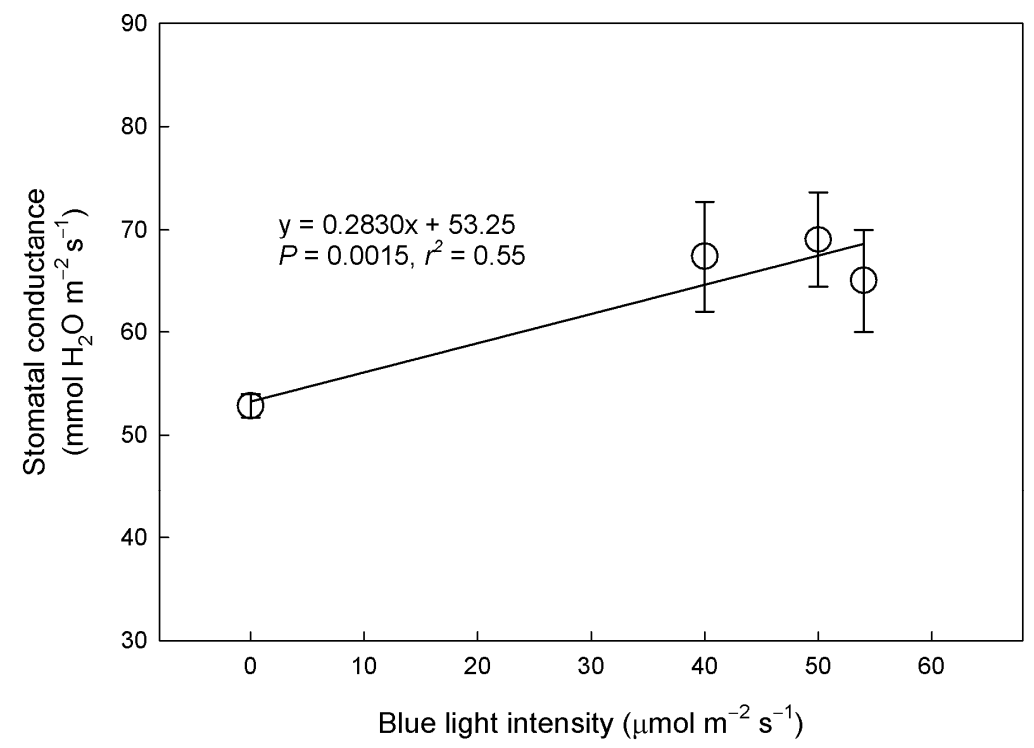

Figure 4. Correlation of the stomatal conductance of Ocimum basilicum with irradiated blue light intensity. Plants were grown under five different combinations of red, green, and blue LEDs with the same light intensity for 14 days. Values are the means of three or six replicates. Error bars indicate the standard error.

Red and blue light are known to regulate stomatal opening in distinct ways that include the photosynthetic-active radiation-dependent pathway, which occurs via the guard cell response to reduced intercellular $\mathrm{CO}_{2}$ concentrations and is stimulated mostly by red light, and the blue light-specific pathway, which is activated by blue light [26-28]. They act additively on stomatal opening, with blue light reported to mediate stomatal opening at nearly a 10 times lower intensity than red light [16], thus playing a primary role in regulating the stomatal aperture. An increased stomatal aperture leads to elevated stomatal conductance, which represents the capacity of carbon uptake through the stomata, resulting in a high photosynthetic rate of the plants. Correspondingly, the $\mathrm{R}_{100}$ treatment showed a lower photosynthetic rate than the other treatments throughout the experiment, most likely due to the lower stomatal conductance caused by the absence of blue light.

The photosynthetic rates of the $\mathrm{R}_{31} \mathrm{G}_{42} \mathrm{~B}_{27}$ and $\mathrm{R}_{75} \mathrm{G}_{25}$ treatments also gradually decreased during the experimental period, despite the fact that they showed similar stomatal conductance to the $\mathrm{R}_{75} \mathrm{~B}_{25}$ and $\mathrm{R}_{60} \mathrm{G}_{20} \mathrm{~B}_{20}$ treatments. The $\mathrm{R}_{31} \mathrm{G}_{42} \mathrm{~B}_{27}$ treatment had the lowest proportion of red and blue light ( $58 \%$ of the total light intensity); it thus displayed a lower photosynthetic rate than the $\mathrm{R}_{75} \mathrm{~B}_{25}$ and $\mathrm{R}_{60} \mathrm{G}_{20} \mathrm{~B}_{20}$ treatments with higher red and blue light proportions. As red and blue light is more highly absorbed by leaves than green light [29], it is assumed that plants grown under the $R_{31} G_{42} B_{27}$ treatment received less photosynthetically available light than the other treatments. The decreased photosynthetic rate of the $R_{75} \mathrm{G}_{25}$ treatment was possibly associated with the low $\mathrm{Fv} / \mathrm{Fm}$ value, indicating the dysfunction of the photosynthetic apparatus of the $\mathrm{R}_{75} \mathrm{G}_{25}$ treatment. Previous studies have suggested that blue light contributes to maintaining the normal function of PSII by boosting the repair rate of PSII; therefore, the Fv/Fm value of plants could decrease if blue light is absent in the growth light [30,31]. However, in the present study, only the Fv/Fm value of the $R_{75} G_{25}$ treatment, but not that of the $R_{100}$ treatment, decreased. The Fv/Fm value usually increases with decreasing light intensity; however, a previous study reported that considerably low light intensity $\left(100 \mu \mathrm{mol} \mathrm{m}^{-2} \mathrm{~s}^{-1}\right)$ could induce a lower Fv $/ \mathrm{Fm}$ value than intermediate light intensity ( 200 and $400 \mu \mathrm{mol} \mathrm{m}^{-2} \mathrm{~s}^{-1}$ ) [32]. Considering that the spectral absorptance and relative quantum efficiency are lower for green light than for red light $[29,33]$, the number of quanta absorbed by the plants and the efficiency of photosynthesis of the quanta could have affected the operation of the photosynthetic 
system of the plants together with the presence of blue light, causing the lowest $\mathrm{Fv} / \mathrm{Fm}$ value in the $R_{75} G_{25}$ treatment.

Green light reverses the stomatal opening induced by blue light in several species, and the reversal of opening is proportional to the B:G ratio [20,34]. Bouly et al. [35] suggested that green light deactivates blue-light-absorbing cryptochrome photoreceptors. However, in the present study, the stomatal conductance values of the $R_{60} G_{20} B_{20}$ and $R_{31} G_{42} B_{27}$ treatments, which had $20 \%$ and $42 \%$ of green light, respectively, were not significantly different from those of the $\mathrm{R}_{75} \mathrm{~B}_{25}$ treatment (Figure $3 \mathrm{~B}$ ), indicating that the adverse effect of green light on blue light-induced stomatal opening did not appear in sweet basil. Furthermore, the $R_{75} G_{25}$ treatment showed similar stomatal conductance to the $R_{60} G_{20} B_{20}$ and $R_{31} G_{42} B_{27}$ treatments, which contained blue light throughout the experimental period, and it was not lower than that of the $\mathrm{R}_{75} \mathrm{~B}_{25}$ treatment until 7DAT. Thus, although blue light has a pivotal impact on stomatal opening, green light also slightly enhances the stomatal aperture in comparison with red light.

Our results were somewhat different from those of previous studies that showed a clear adverse effect of green to blue light on stomatal opening $[34,36,37]$. This incoherence might be because the experimental approach and plant species were different between these studies and the present study. Talbott et al. [34] used optical filters to provide the specific light treatments and measured the stomatal aperture on detached epidermal strips of leaves after a few hours of light treatment, and Kim et al. [36] used a broad-spectrum fluorescent lamp for green light treatment and measured the stomatal conductance of plants in the morning. The light duration treatment and measurement time of stomatal conductance could be the factors that resulted in different results. According to Talbott et al. [38], the reversal of blue light-induced stomatal opening by green light only occurred in the morning and not in the afternoon, which was possibly due to the changing phases of guard cell osmoregulation over the course of a day. Guard cell osmoregulation shifts from potassium accumulation-dependent in the morning to sucrose accumulation-dependent in the afternoon, which indicates that stomatal opening is regulated by different mechanisms over time [39].

Overall, the measurement of the growth and photosynthetic parameters indicated that the plants displayed similar growth; however, their photosynthetic rates were different due to the different stomatal conductance based on the irradiated light quality. Therefore, the water usage of plants could be explained by their stomatal responses, without considering the size of the plants or the canopy leaf temperatures, which can affect the evapotranspiration rate on the leaf surface.

\subsection{Effect of Light Quality on the Water Use of Basil Plants}

The daily evapotranspiration of sweet basil was measured using load cells for two weeks, and the measured values are shown in Figure 5. The daily evapotranspiration of the plants gradually increased as they grew, regardless of the treatments. Overall, the amount of daily evapotranspiration was higher in the $R_{75} B_{25}, R_{60} G_{20} B_{20}, R_{31} G_{42} B_{27}$, and $R_{75} G_{25}$ treatments than in the $\mathrm{R}_{100}$ treatment. A difference in evapotranspiration amount among the treatments was detected at 1DAT $(p=0.0159)$ (Figure 5). Although plant size is the most important factor that determines the water use of plants [40], there was no significant difference in plant size among the treatments in the present study (Table 1). Therefore, the water use of the plants was mostly influenced by the extent of the stomatal aperture at the beginning of the experiment, which is an immediate response of plants to light quality. Rapid changes in stomatal opening under different light qualities have been reported in a previous study [20]. 


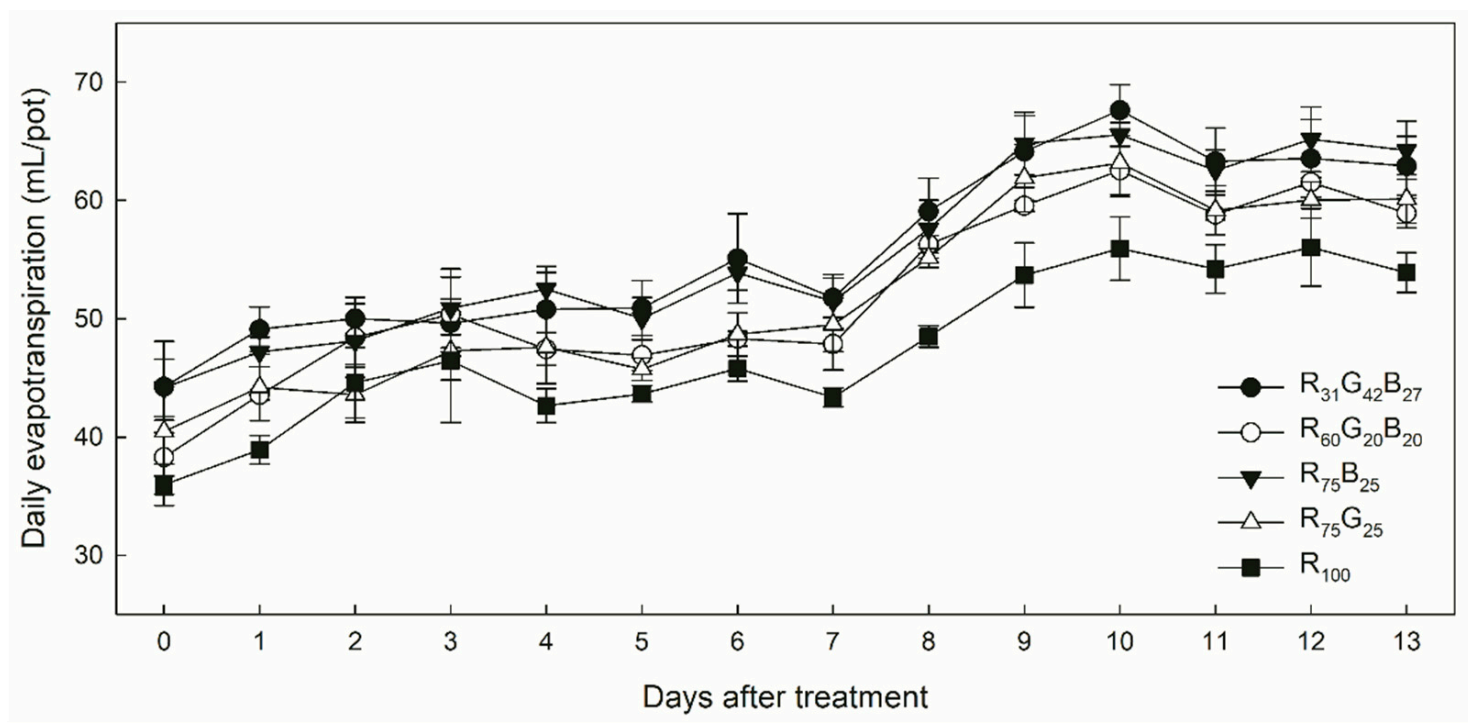

Figure 5. Daily evapotranspiration amount of Ocimum basilicum grown under five different combinations of red, green, and blue LEDs with the same light intensity for 14 days. The numbers after each waveband indicate the ratios of the intensities. The $R_{31} G_{42} B_{27}$ treatment mimics the sunlight spectrum measured in the experimental greenhouse. Pot weights were measured using load cells, and the decrease in weight recorded every $30 \mathrm{~min}$ was used to calculate the amount of evapotranspiration. Error bars indicate the standard error $(n=3)$.

A difference in water use between the $\mathrm{R}_{100}$ treatment and the other treatments, which contained green or blue light, was observed and became more evident in the second week than in the first week (Figures 5 and 6). During the first week, the amount of water used by the $R_{100}$ and $R_{75} G_{25}$ treatments was significantly lower than that in the $R_{31} G_{42} B_{27}$ treatment (Figure 6). However, during the second week, water use in the $\mathrm{R}_{75} \mathrm{G}_{25}$ treatment caught up with that in the $R_{31} G_{42} B_{27}$ treatment, and only the $R_{100}$ treatment displayed a smaller amount of water use than the other treatments. This was because green light increased the stomatal conductance of plants compared to red light, playing a similar role to that of blue light in the $\mathrm{R}_{75} \mathrm{G}_{25}$ treatment. Therefore, the total amount of water used by the plants was higher in the $R_{75} G_{25}, R_{75} B_{25}, R_{60} G_{20} B_{20}$, and $R_{31} G_{42} B_{27}$ treatments than in the $R_{100}$ treatment $\left(663.5,726.5,728.7,778.0\right.$, and $782.1 \mathrm{~mL}$ of water per pot for the $\mathrm{R}_{100}, \mathrm{R}_{75} \mathrm{G}_{25}$, $R_{60} G_{20} B_{20}, R_{75} B_{25}$, and $R_{31} G_{42} B_{27}$ treatments, respectively), during the entire experimental period. The difference between the highest and lowest amounts was $118.6 \mathrm{~mL}$. Our results showed that the stomatal response of plants led to different water usage by the plants depending on the quality of the irradiated light.

There has been considerable effort to promote the water use efficiency of indoor plant production systems. Our results showed that light quality could be one of the ways to regulate the water usage of plants during production. In the present study, the water usage of plants was assessed for only two weeks; therefore, the difference among the treatments was not large. However, if we look at growing plants with very limited water resources (i.e., aerospace) [41], the light quality will considerably affect the amount of water required for plant production. Based on our results, further experiments could be conducted to investigate whether the plants would maintain normal photosynthetic activities with relatively low water use if they are grown under only red light with high $\mathrm{CO}_{2}$ concentrations, which is enough to compensate for their low stomatal conductance. If so, growing plants at a high $\mathrm{CO}_{2}$ concentration under light conditions that lower the stomatal aperture of the plants could be a way of reducing water consumption in indoor plant cultivation. 


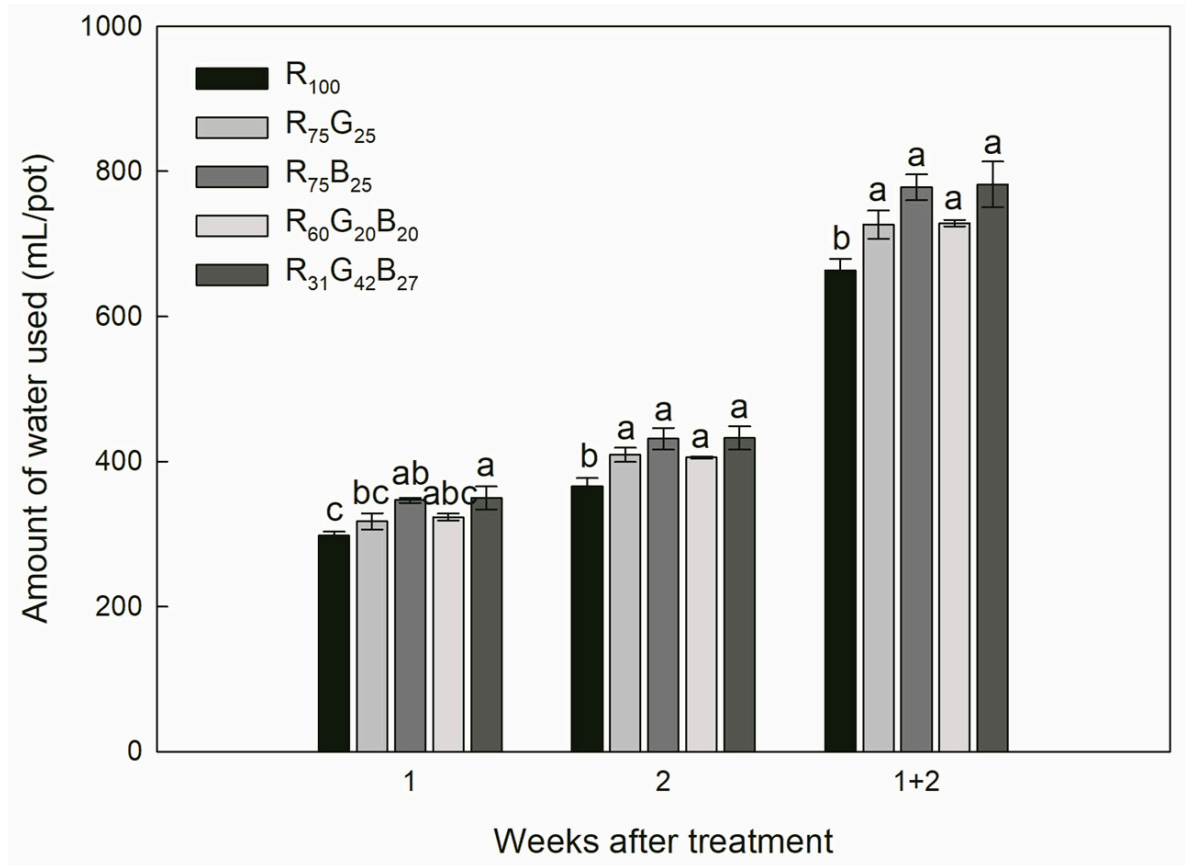

Figure 6. Total amount of water used by Ocimum basilicum grown under five different combinations of red, green, and blue LEDs with the same light intensity for 14 days. The numbers after each waveband indicate the ratios of the intensities. The $\mathrm{R}_{31} \mathrm{G}_{42} \mathrm{~B}_{27}$ treatment mimics the sunlight spectrum measured in the experimental greenhouse. Values shown represent the total water usage of the first week, second week, and the entire experimental period. Pot weights were measured using load cells, and the decrease in weight recorded every 30 min was used to calculate the amount of water used. Mean separation followed analysis of variance (ANOVA) with Duncan's multiple range test at $\alpha=0.05$. Means with the same letter are not significantly different. Error bars indicate the standard error $(n=3)$.

\subsection{Stomatal Development under Different Light Quality}

In the present study, stomatal size and density of sweet basil grown under different spectral treatments were measured to assess the effect of light quality on the stomatal development of the plants. There were no significant differences among the treatments in guard cell length, guard cell width, and pore length at both 7DAT and 14DAT (Table 2). However, stomatal density was higher in plants grown under LEDs with blue light $\left(\mathrm{R}_{75} \mathrm{~B}_{25}\right.$, $\mathrm{R}_{60} \mathrm{G}_{20} \mathrm{~B}_{20}$, and $\mathrm{R}_{31} \mathrm{G}_{42} \mathrm{~B}_{27}$ ) than in those under the $\mathrm{R}_{100}$ treatment at 14DAT (Table 2 and Figure 7). The stomatal density of the $R_{75} G_{25}$ treatment was not higher than that of the $R_{100}$ treatment; however, it was not significantly different from that of the $R_{75} B_{25}$ treatment. The different stomatal densities among the treatments were detected only at 14DAT, indicating that newly developed stomata required time to acclimate to the given light quality. According to Schoch et al. [42], the stomatal development of new leaves is affected by the light condition to which mature leaves have been exposed. The stomatal development of the newly produced leaves might have been affected by the quality of light treatment applied to the existing leaves in the present study, displaying different stomatal densities among the treatments at 14DAT. 
Table 2. Effects of different spectral treatments on the stomatal development of Ocimum basilicum grown under five different combinations of red, green, and blue LEDs with the same light intensity for 14 days after the treatment (DAT). The numbers after each waveband indicate the ratios of the intensities. The $\mathrm{R}_{31} \mathrm{G}_{42} \mathrm{~B}_{27}$ treatment mimics the sunlight spectrum measured in the experimental greenhouse. For the measurement of stomatal density, $n=6$, and for the other measurements, 30 stomata of each six samples $(n=180)$ were analyzed for each treatment. Mean separation followed analysis of variance (ANOVA) with Duncan's multiple range test at $\alpha=0.05$.

\begin{tabular}{ccccccccc}
\hline \multirow{2}{*}{ Treatment } & Guard Cell Length $(\mu \mathrm{m})$ & \multicolumn{2}{c}{ Guard Cell Width $(\mu \mathrm{m})$} & \multicolumn{2}{c}{ Pore Length $(\mu \mathrm{m})$} & $\begin{array}{c}\text { Stomatal Density } \\
(\text { Stomata mm }\end{array}$ \\
\cline { 2 - 8 } & 7DAT & 14DAT & 7DAT & 14DAT & 7DAT & 14DAT & 7DAT & 14DAT \\
\hline $\mathrm{R}_{100}$ & 35.5 & 33.2 & 20.5 & 19.3 & 26.7 & 24.3 & 60.2 & $55.7 \mathrm{c}$ \\
$\mathrm{R}_{75} \mathrm{G}_{25}$ & 35.5 & 32.8 & 20.4 & 18.7 & 27.1 & 23.7 & 59.8 & $59.0 \mathrm{bc}$ \\
$\mathrm{R}_{75} \mathrm{~B}_{25}$ & 36.2 & 32.4 & 20.5 & 19.2 & 27.4 & 23.3 & 61.0 & $63.2 \mathrm{ab}$ \\
$\mathrm{R}_{60} \mathrm{G}_{20} \mathrm{~B}_{20}$ & 35.6 & 33.3 & 20.0 & 19.3 & 27.2 & 24.0 & 61.7 \\
$\mathrm{R}_{31} \mathrm{G}_{42} \mathrm{~B}_{27}$ & 35.9 & 33.3 & 20.1 & 19.5 & 27.3 & 23.9 & 57.5 & $67.3 \mathrm{a}$ \\
\hline Significance & NS & NS & NS & NS & NS & NS & NS & $* * *$ \\
\hline
\end{tabular}

Means followed by the same letter within a column are not significantly different. NS and ${ }^{* * *}$ indicate non-significance and significance at $p<0.001$, respectively.
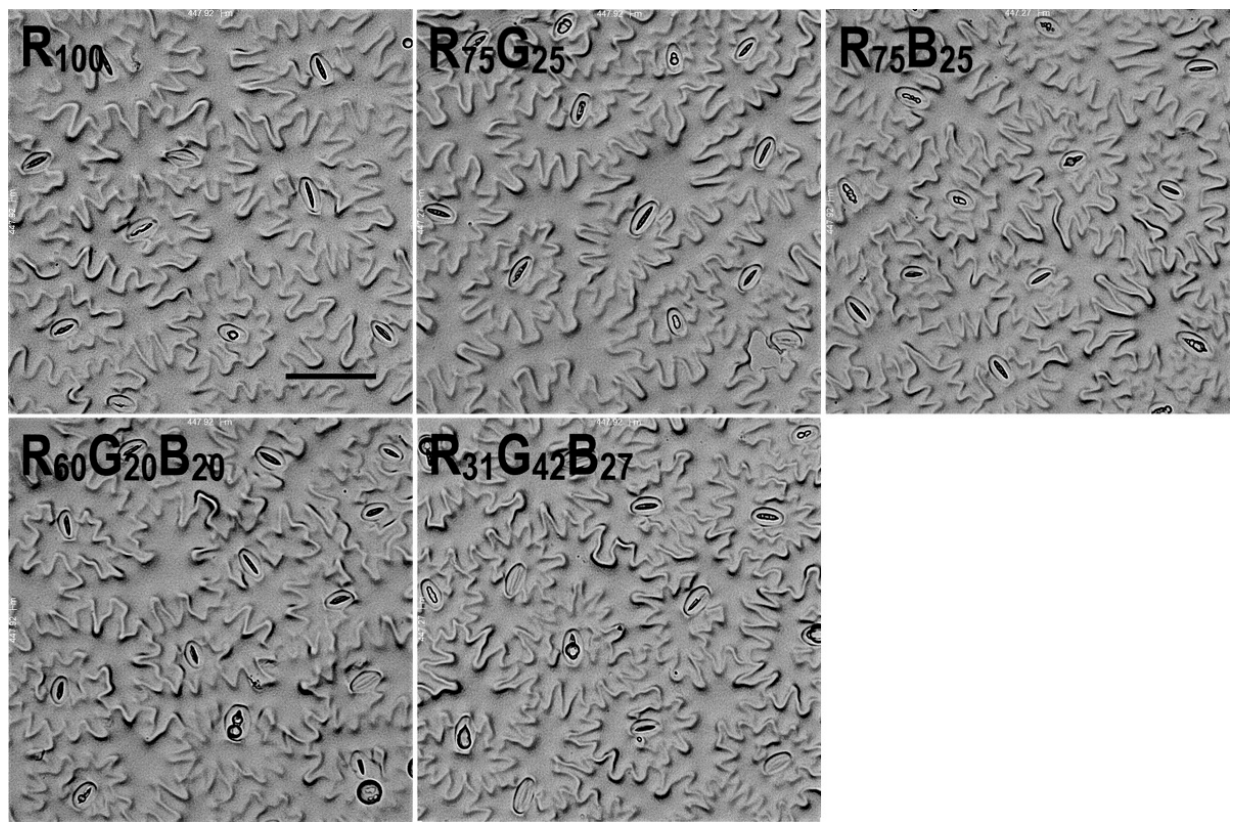

Figure 7. Effects of different spectral treatments on the stomatal development of Ocimum basilicum grown under five different combinations of red, green, and blue LEDs with the same light intensity for 14 days. The numbers after each waveband indicate the ratios of the intensities. The $R_{31} G_{42} B_{27}$ treatment mimics the sunlight spectrum measured in the experimental greenhouse. Scale bar is $100 \mu \mathrm{m}$.

Light-induced stomatal responses are regulated by several photoreceptors, including blue/UV-A light-absorbing cryptochromes (CRY) and phototropins, and red/far-red lightabsorbing phytochromes (phy) [43-45]. Kang et al. [46] reported that stomatal development in Arabidopsis thaliana was inhibited under blue and red light in the loss-of-function mutants of CRY and phyB, respectively, suggesting that CRY and phyB are involved in the stomatal development process stimulated by light quality. In our study, the stomatal density of plants increased with increasing blue light intensity $(p=0.0024)$ (Figure 8A), which is consistent with the results of a previous study in which sweet basil was grown in a greenhouse with supplemental LED light [47]. Therefore, blue light appears to promote the generation of stomata more effectively than red light. In addition, a positive correlation was observed between stomatal density and the combined intensity of green and blue 
light $(p=0.0029)$ (Figure 8B). This correlation indicates that green light increases the stomatal density of plants along with blue light, which was supported by the observation that the stomatal density of the $R_{75} G_{25}$ treatment was not significantly lower than that of the $\mathrm{R}_{75} \mathrm{~B}_{25}$ treatment in the present study. A previous study conducted on cherry tomatoes also showed higher stomatal density under monochromatic green light than under monochromatic red light [17].
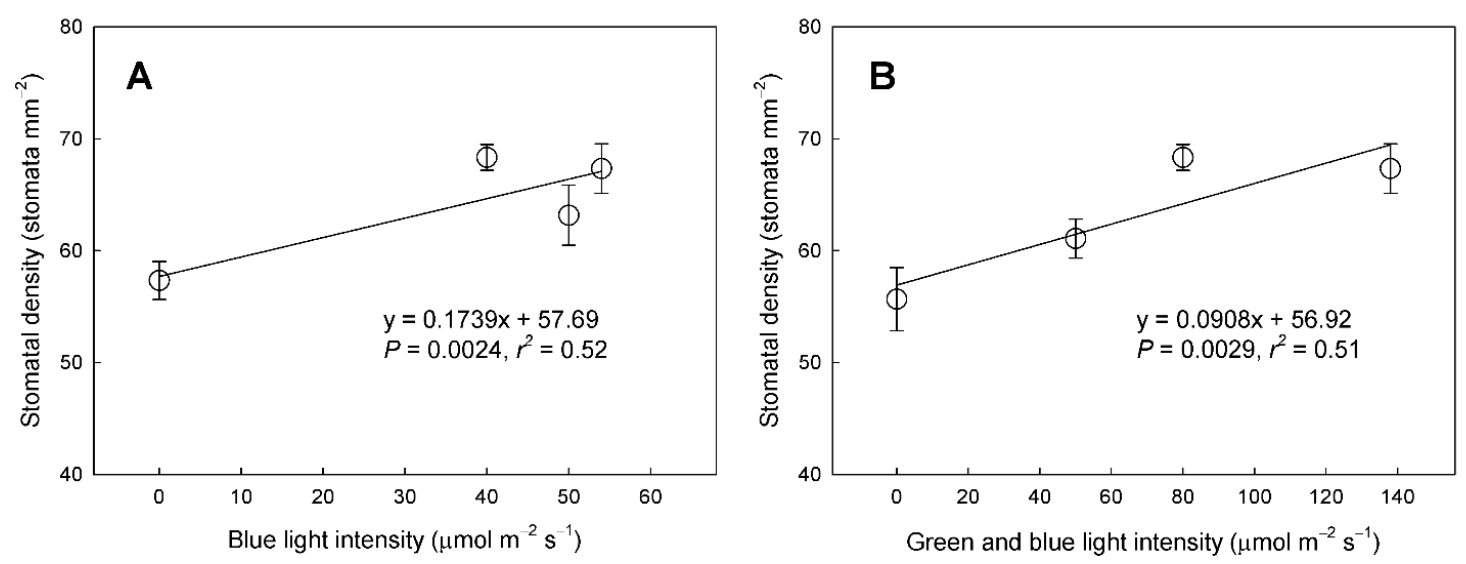

Figure 8. Correlations of the stomatal density of Ocimum basilicum with irradiated (A) blue light intensity and (B) green and blue light intensity. Plants were grown under five different combinations of red, green, and blue LEDs with the same light intensity for 14 days. Values are the means of three or six replicates. Error bars indicate the standard error.

The regression analysis performed on the stomatal density and conductance data showed a positive correlation between these factors, indicating that an increase in stomatal density contributed to an increase in stomatal conductance in plants $(p=0.015)$ (Figure 9). As the experiment progressed, not only stomatal opening but also stomatal density of the plants developed differently under the given light quality, resulting in different transpiration and water use among the treatments. The contribution of stomatal density to the different water use of plants is shown in Figures 5 and 6, where the difference among the treatments was more evident later in the experiment than at the beginning. The different stomatal development of the plants and increased water usage following the increased size of the plants might have widened the gap among the treatments as the study progressed.

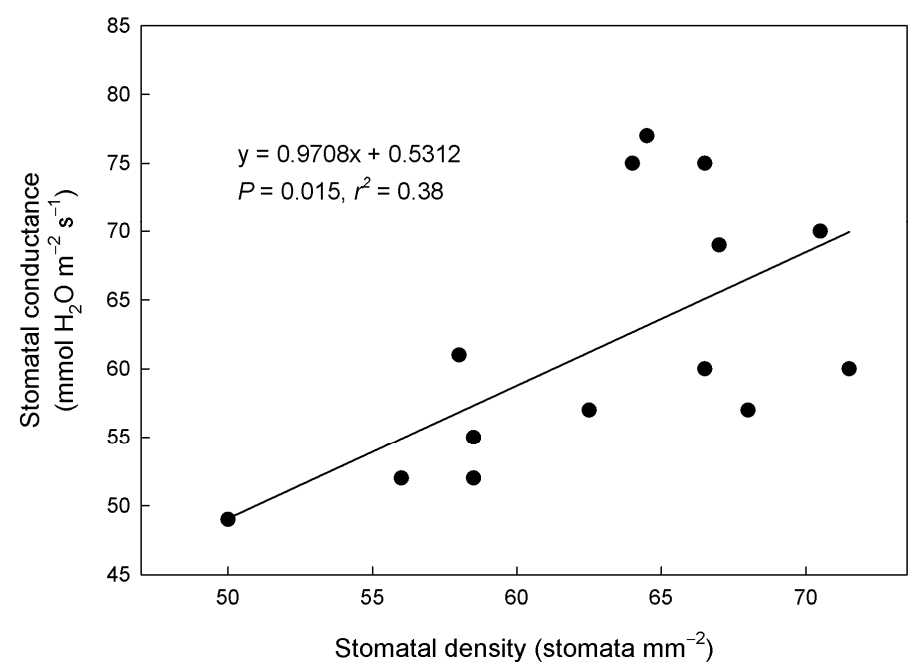

Figure 9. Relationship between the stomatal conductance and stomatal density of Ocimum basilicum. Plants were grown under five different combinations of red, green, and blue LEDs with the same light intensity for 14 days. The regression line was fitted through the data of all the treatments. 


\section{Conclusions}

In the present study, light quality significantly affected the water use of sweet basil plants, together with the photosynthetic activities and stomatal density. Plants grown under LEDs with blue light showed a higher photosynthetic rate and stomatal conductance than plants grown under only red light. Increased stomatal conductance under blue light resulted in increased water usage by the plants. Although green light has been reported to reverse the stomatal opening induced by blue light, our results showed that green light increased the stomatal conductance and density of the plants along with blue light, thereby increasing the water use of the plants compared to red light. Plants grown under combined red and green light displayed similar water use to plants grown under blue LEDs. In conclusion, light quality affects the water use of plants by regulating the stomatal conductance of plants, and both the changes in stomatal aperture and density seems to contribute to the different water use of plants under different light qualities.

Author Contributions: S.L. and J.K. contributed to the conception and design of the study. S.L. carried out the measurements and organized the database. S.L. and J.K. performed the data analysis. S.L. wrote the manuscript. J.K. provided guidance on the whole study and improved the manuscript. All authors have read and agreed to the published version of the manuscript.

Funding: This study was supported by a Korea University Grant.

Institutional Review Board Statement: Not applicable.

Informed Consent Statement: Not applicable.

Data Availability Statement: The data presented in this study are available on request from the corresponding author.

Conflicts of Interest: The authors declare no conflict of interest.

\section{References}

1. Kozai, T.; Niu, G. Role of the plant factory with artificial lighting (PFAL) in urban areas. In Plant Factory, 2nd ed.; Kozai, T., Niu, G., Takagaki, M., Eds.; Elsevier: Amsterdam, The Netherlands, 2020; pp. 7-34.

2. Bula, R.J.; Morrow, R.C.; Tibbitts, T.W.; Barta, D.J.; Ignatius, R.W.; Martin, T.S. Light-emitting diodes as a radiation source for plants. HortScience 1991, 26, 203-205. [CrossRef]

3. Massa, G.D.; Kim, H.H.; Wheeler, R.M.; Mitchell, C.A. Plant productivity in response to LED lighting. HortScience 2008, 43, 1951-1956. [CrossRef]

4. Kong, Y.; Nemali, A.; Mitchell, C.; Nemali, K. Spectral quality of light can affect energy consumption and energy-use efficiency of electrical lighting in indoor lettuce farming. HortScience 2019, 54, 865-872. [CrossRef]

5. Pennisi, G.; Pistillo, A.; Orsini, F.; Cellini, A.; Spinelli, F.; Nicola, S.; Fernandez, J.A.; Crepaldi, A.; Gianquinto, G.; Marcelis, L.F.M. Optimal light intensity for sustainable water and energy use in indoor cultivation of lettuce and basil under red and blue LEDs. Sci. Hortic. 2020, 272, 109508. [CrossRef]

6. Morrow, R.C. LED lighting in horticulture. HortScience 2008, 43, 1947-1950. [CrossRef]

7. Zheng, L.; He, H.; Song, W. Application of light-emitting diodes and the effect of light quality on horticultural crops: A review. HortScience 2019, 54, 1656-1661. [CrossRef]

8. Larsen, D.H.; Woltering, E.J.; Nicole, C.C.S.; Marcelis, L.F.M. Response of basil growth and morphology to light intensity and spectrum in a vertical farm. Front. Plant Sci. 2020, 11, 597906. [CrossRef]

9. Silvestri, C.; Caceres, M.E.; Ceccarelli, M.; Pica, A.L.; Rugini, E.; Cristofori, V. Influence of continuous spectrum light on morphological traits and leaf anatomy of hazelnut plantlets. Front. Plant Sci. 2019, 10, 1318. [CrossRef]

10. Goins, G.D.; Yorio, N.C.; Sanwo, M.M.; Brown, C.S. Photomorphogenesis, photosynthesis, and seed yield of wheat plants grown under red light-emitting diodes (LEDs) with and without supplemental blue lighting. J. Exp. Bot. 1997, 48, 1407-1413. [CrossRef]

11. Christie, J.M.; Briggs, W.R. Blue light sensing in higher plants. J. Biol. Chem. 2001, 276, 11457-11460. [CrossRef]

12. Yorio, N.C.; Goins, G.D.; Kagie, H.R.; Wheeler, R.M.; Sager, J.C. Improving spinach, radish, and lettuce growth under red light-emitting diodes (LEDs) with blue light supplementation. HortScience 2001, 36, 380-383. [CrossRef]

13. Matsuda, R.; Ohashi-Kaneko, K.; Fujiwara, K.; Goto, E.; Kurata, K. Photosynthetic characteristics of rice leaves grown under red light with or without supplemental blue light. Plant Cell Physiol. 2004, 45, 1870-1874. [CrossRef] [PubMed]

14. Kim, H.H.; Goins, G.D.; Wheeler, R.M.; Sager, J.C. Green-light supplementation for enhanced lettuce growth under red-and blue-light-emitting diodes. HortScience 2004, 39, 1617-1622. [CrossRef]

15. Zhang, T.; Maruhnich, S.A.; Folta, K.M. Green light induces shade avoidance symptoms. Plant Physiol. 2011, 157, 1528-1536. [CrossRef] [PubMed] 
16. Sharkey, T.D.; Raschke, K. Effect of light quality on stomatal opening in leaves of Xanthium strumarium L. Plant Physiol. 1981, 68, 1170-1174. [CrossRef] [PubMed]

17. XiaoYing, L.; ShiRong, G.; ZhiGang, X.; XueLei, J.; Tezuka, T. Regulation of chloroplast ultrastructure, cross-section anatomy of leaves, and morphology of stomata of cherry tomato by different light irradiations of light-emitting diodes. HortScience 2011, 46, 217-221. [CrossRef]

18. Savvides, A.; Fanourakis, D.; van Ieperen, W. Co-ordination of hydraulic and stomatal conductances across light qualities in cucumber leaves. J. Exp. Bot. 2012, 63, 1135-1143. [CrossRef]

19. Wang, J.; Lu, W.; Tong, Y.; Yang, Q. Leaf morphology, photosynthetic performance, chlorophyll fluorescence, stomatal development of lettuce (Lactuca sativa L.) exposed to different ratios of red light to blue light. Front. Plant Sci. 2016, 7, 250. [CrossRef]

20. Frechilla, S.; Talbott, L.D.; Bogomolni, R.A.; Zeiger, E. Reversal of blue light-stimulated stomatal opening by green light. Plant Cell Physiol. 2000, 41, 171-176. [CrossRef] [PubMed]

21. Pennisi, G.; Blasioli, S.; Cellini, A.; Maia, L.; Crepaldi, A.; Braschi, I.; Spinelli, F.; Nicola, S.; Fernandez, J.A.; Stanghellini, C.; et al. Unraveling the role of red:blue LED lights on resource use efficiency and nutritional properties of indoor grown sweet basil. Front. Plant Sci. 2019, 10, 305. [CrossRef] [PubMed]

22. Bin, Z.; Qingya, W.; Canming, T. Anatomic analysis on heterosis in three transgenic bt pest-resistant hybrid cotton (G. hirsutum L.). Acta Agron. Sin. 2008, 34, 496-505.

23. Schenkels, L.; Saeys, W.; Lauwers, A.; Maurice, P. Green light induces shade avoidance to alter plant morphology and increases biomass production in Ocimum basilicum L. Sci. Hortic. 2020, 261, 109002. [CrossRef]

24. Zeiger, E.; Field, C. Photocontrol of the functional coupling between photosynthesis and stomatal conductance in the intact leaf: Blue light and PAR-dependent photosystems in guard cells. Plant Physiol. 1982, 70, 370-375. [CrossRef]

25. Hogewoning, S.W.; Trouwborst, G.; Maljaars, H.; Poorter, H.; van Ieperen, W.; Harbinson, J. Blue light dose-responses of leaf photosynthesis, morphology, and chemical composition of Cucumis sativus grown under different combinations of red and blue light. J. Exp. Bot. 2010, 61, 3107-3117. [CrossRef]

26. Zeiger, E. The biology of stomatal guard cells. Annu. Rev. Plant Physiol. 1983, 34, 441-474. [CrossRef]

27. Assmann, S.M.; Shimazaki, K. The multisensory guard cell. Stomatal responses to blue light and abscisic acid. Plant Physiol. 1999, 119, 809-816. [CrossRef]

28. Inoue, S.; Kinoshita, T. Blue light regulation of stomatal opening and the plasma membrane $\mathrm{H}^{+}$-ATPase. Plant Physiol. 2017, 174, 531-538. [CrossRef]

29. McCree, K.J. The action spectrum, absorptance and quantum yield of photosynthesis in crop plants. Agric. Meteorol. 1971, 9 , 191-216. [CrossRef]

30. Thum, K.E.; Kim, M.; Christopher, D.A.; Mullet, J.E. Cryptochrome 1, cryptochrome 2, and phytochrome A co-activate the chloroplast $p s b D$ blue light-responsive promoter. Plant Cell 2001, 13, 2747-2760. [PubMed]

31. Miao, Y.; Chen, Q.; Qu, M.; Gao, L.; Hou, L. Blue light alleviates 'red light syndrome' by regulating chloroplast ultrastructure, photosynthetic traits and nutrient accumulation in cucumber plants. Sci. Hortic. 2019, 257, 108680. [CrossRef]

32. Fu, W.; Li, P.; Wu, Y. Effects of different light intensities on chlorophyll fluorescence characteristics and yield in lettuce. Sci. Hortic. 2012, 135, 45-51. [CrossRef]

33. Sager, J.C.; Smith, W.O.; Edwards, J.L.; Cyr, K.L. Photosynthetic efficiency and phytochrome photoequilibria determination using spectral data. Trans. ASAE 1988, 31, 1882-1889. [CrossRef]

34. Talbott, L.D.; Nikolova, G.; Ortiz, A.; Shmayevich, I.; Zeiger, E. Green light reversal of blue-light-stimulated stomatal opening is found in a diversity of plant species. Am. J. Bot. 2002, 89, 366-368. [CrossRef] [PubMed]

35. Bouly, J.P.; Schleicher, E.; Dionisio-Sese, M.; Vandenbussche, F.; Van Der Straeten, D.; Bakrim, N.; Meier, S.; Batschauer, A.; Galland, P.; Bittl, R.; et al. Cryptochrome blue light photoreceptors are activated through interconversion of flavin redox states. J. Biol. Chem. 2007, 282, 9383-9391. [CrossRef]

36. Kim, H.H.; Goins, G.D.; Wheeler, R.M.; Sager, J.C. Stomatal conductance of lettuce grown under or exposed to different light qualities. Ann. Bot. 2004, 94, 691-697. [CrossRef] [PubMed]

37. Bian, Z.; Zhang, X.; Wang, Y.; Lu, C. Improving drought tolerance by altering the photosynthetic rate and stomatal aperture via green light in tomato (Solanum lycopersicum L.) seedlings under drought conditions. Environ. Exp. Bot. 2019, 167, 103844. [CrossRef]

38. Talbott, L.D.; Hammad, J.W.; Harn, L.C.; Nguyen, V.H.; Patel, J.; Zeiger, E. Reversal by green light of blue light-stimulated stomatal opening in intact, attached leaves of Arabidopsis operates only in the potassium-dependent, morning phase of movement. Plant Cell Physiol. 2006, 47, 332-339. [CrossRef] [PubMed]

39. Talbott, L.D.; Zeiger, E. Central roles for potassium and sucrose in guard-cell osmoregulation. Plant Physiol. 1996, 111, 1051-1057. [CrossRef]

40. Kim, J.; van Iersel, M.W.; Burnett, S.E. Estimating daily water use of two petunia cultivars based on plant and environmental factors. HortScience 2011, 46, 1287-1293. [CrossRef]

41. Monje, O.; Stutte, G.W.; Goins, G.D.; Porterfield, D.M.; Bingham, G.E. Farming in space: Environmental and biophysical concerns. Adv. Space. Res. 2003, 31, 151-167. [CrossRef]

42. Schoch, P.G.; Zinsou, C.; Sibi, M. Dependence of the stomatal index on environmental factors during stomatal differentiation in leaves of Vigna sinensis L. 1. Effect of light intensity. J. Exp. Bot. 1980, 31, 1211-1216. [CrossRef] 
43. Neff, M.M.; Fankhauser, C.; Chory, J. Light: An indicator of time and place. Genes. Dev. 2000, 14, 257-271. [PubMed]

44. Shimazaki, K.; Doi, M.; Assmann, S.M.; Kinoshita, T. Light regulation of stomatal movement. Annu. Rev. Plant Biol. 2007, 58, 219-247. [CrossRef]

45. Inoue, S.; Kinoshita, T.; Matsumoto, M.; Nakayama, K.I.; Doi, M.; Shimazaki, K. Blue light-induced autophosphorylation of phototropin is a primary step for signaling. Proc. Natl. Acad. Sci. USA 2008, 105, 5626-5631. [CrossRef] [PubMed]

46. Kang, C.Y.; Lian, H.L.; Wang, F.F.; Huang, J.R.; Yang, H.Q. Cryptochromes, phytochromes, and COP1 regulate light-controlled stomatal development in Arabidopsis. Plant Cell 2009, 21, 2624-2641. [CrossRef]

47. Jensen, N.B.; Clausen, M.R.; Kjaer, K.H. Spectral quality of supplemental LED grow light permanently alters stomatal functioning and chilling tolerance in basil (Ocimum basilicum L.). Sci. Hortic. 2018, 227, 38-47. [CrossRef] 